\title{
Trabalho e educação popular: diálogos entre educação profissional e educação de jovens e adultos
}

\author{
Work and popular education: \\ dialogue between professional education and young adult formation
}

\author{
Maria Emilia de Castro RODRIGUES ${ }^{1}$ \\ Cláudia Borges COSTA²
}

\begin{abstract}
Resumo
$\mathrm{O}$ artigo apresenta algumas pesquisas do Centro Memória Viva: Documentação e Referência em Educação de Jovens e Adultos, Educação Popular e Movimentos Sociais do Centro-Oeste (CMV), em diálogo entre educação de jovens e adultos (EJA), educação profissional eeducação popular: Movimento de Educação de Base em Goiás e EJA na SME de Goiânia: história e memória. A gênese do CMV foi o Museu Virtual da Educação em Goiás, da pesquisa Infovias e Educação. Trata-se de pesquisa bibliográfica e documental, com aporte teórico da educação popular, EJA, trabalho, educação profissional, arquivística, memória e história oral, na organização disponibilizada ao público.
\end{abstract}

Palavras-chave: Memória. EJA. Educação Popular. Educação Profissional.
Abstract

The following article contains interpretations focusing in a few researches from Centro Memória Viva: Documentation and Reference in Education of Young and Adults, Popular Education and Social Movements of the Center-West (CMV), in dialogue between you thand adult education (EJA), professional education and popular education: Basic Education Movement in Goiás and EJA in Goiânia's SME: history and memory. The creation of the center in question was the Virtual Museum of Education in Goiás, the research project Infovias e Educação. It is a bibliographic and documentary research, with the theoretical contribution of popular education, EJA, work, professional education, archival, memory and oral history, in the organization made available to the public.

Keywords: Memory. EJA. Popular Education. Professional Education.

1 Doutorado em Educação; Grupo de pesquisa CNPq Estado, Política e Educação; professora da Universidade Federal de Goiás. End.: Rua Dr. Gustavo Alves do Prado, Q. 17, L. 10, Bairro Santo Hilário, CEP: 74780-240. Tel.: (62) 32096210; Email: <me.castrorodrigues@gmail.com>.

2 Doutora em Educação; Grupo de pesquisa Centro Memória Viva; vínculo profissional Secretaria Municipal de Educação. Email: <cbc2111@gmail.com>.

\begin{tabular}{|l|l|l|l|l|l|} 
R. Educ. Públ. & Cuiabá & v. 27 & n. 65/1 & p. $447-467$ & maio/ago. 2018 \\
\hline
\end{tabular}




\section{Primeiras palavras}

A atividade de trabalho é atravessada de história Yves Schwartz (2016, p. 23).

O presente artigo visa apresentar as pesquisas por nós coordenadas e/ou desenvolvidas na Região Centro-Oeste no âmbito da educação de jovens e adultos e educação profissional na perspectiva da educaçáo popular (EP). Tratam-se das pesquisas: a) do Centro Memória Viva(CMV) - Documentação e Referência em Educação de Jovens e Adultos (EJA), Educação Popular e Movimentos Sociais do Centro-Oeste, o qual foi criado em 2010, com vistas a constituir um banco de dados digital sobre a memória, documentação e história vivenciada nos sistemas oficiais de ensino (secretarias estaduais e municipais de educação), movimentos de educação popular e movimentos sociais vinculados à EJA. O banco de dados vem sendo desenvolvido em rede no Centro-Oeste pela Universidade Federal de Goiás (UFG), que o coordena, Universidade Federal de Mato Grosso (UFMT), Universidade Federal de Mato Grosso do Sul (UFMS) e Universidade de Brasília (UnB). A coordenação geral está com a professora doutora Maria Margarida Machado e em Goiás a pesquisa conta com recursos advindos da Fundação de Amparo à Pesquisa do Estado de Goiás (Fapeg). Nesse sentido, atuamos com os subprojetos Movimento de Educação de Base em Goiás (MEB Goiás) e da Educação de Jovens e Adultos na SME de Goiânia: história e memória; b) e do Observatório da Educação (Obeduc), com a pesquisa denominada Desafios da Educação de Jovens e Adultos integrada à Educação Profissional: identidades dos sujeitos, currículo integrado, mundo do trabalho e ambientes/ mídias virtuais, vinculada e financiada pela Coordenação de Aperfeiçoamento de Pessoal de Nível Superior (Capes), conforme Edital Obeduc-2012, Projeto n. 13769. Essa pesquisa, desenvolvida em rede com a Universidade Federal de Goiás (UFG), que a coordena, Universidade Federal do Espírito Santo (UFES) e Universidade de Brasília (UnB), contou inicialmente com acoordenação da Prof. Dra. Maria Margarida Machado (jan./2013 a fev./2016) e a seguir da Prof. Dra. Maria Emilia de Castro Rodrigues (fev./2016 a nov./2017).

Os objetivos da pesquisa do CMV voltam-se para a identificação, classificação, organização, análise documental e disponibilização online de materiais da educação, especificamente da EJA, educação popular e movimentos sociais, que constituem a memória passada e atual, a fim de ser estudada, analisada, formando narrativas advindas da percepção de pesquisadores e interessados nas temáticas.

O CMV teve suas origens assentadas no Museu Virtual da Educação em Goiás, organizado em 2002, com o projeto de pesquisa Infovias e Educação, tendo sua proposta retomada a partir da reuniâo da Associação Nacional de Pós-Graduação 
e Pesquisa em Educação (Anped), em 2008, em que o Professor Osmar Fávero propiciou reflexóes acerca dos movimentos de educaçáo popular, o que provocou os pesquisadores da UFG a pensaremnuma pesquisa sobre os movimentos de educação popular da década de 1940-1960. Dessa forma, suscitou o fomento ao Museu Virtual da Educação em Goiás, que contou com recursos financeiros, inicialmente, da Secretaria de Educação Continuada, Alfabetização, Diversidade (Secad) e da Secretaria de Educação Profissional e Tecnológica (Setec) a projetos denominados Centros de Referência em EJA, nos anos de 2010 e 2011.

No CMV o trabalho desenvolvido foi composto com o uso efetivo de pesquisa bibliográfica e documental. Inicialmente, os estudos sobre os eixos da pesquisa EJA, Educação Popular e Movimentos Sociais constituíram-se como reflexões necessárias para as reflexões dos pesquisadores. $\mathrm{O}$ acesso às leituras de Brandão (2000), Fávero (2006), Guimarães e Nepomuceno (2009), Paiva (2003), Wanderley (1984), Rodrigues (2008), entre outros, foi essencial para esse momento. Como as discussóes abriram-se para a disponibilidade pública e gratuita do acervo, sentimos a necessidade de buscar outros estudos que pudessem contribuir com a organização e tratamento da documentaçáo. Assim procuramos compreender e estruturar uma forma de reunir, descrever, classificar e digitalizar os documentos produzidos. Tudo isso foi possível utilizando como referência a Norma Brasileira de Descrição Arquivística (Nobrade) ${ }^{3}$.

No que tange à análise documental, recorremos a referenciais como: Pimentel (2001), cuja pesquisa qualitativa apresentou o processo de uma investigação que objetivava compreender as relaçóes entre os objetos de sua pesquisa; Corsetti (2006), que também relata a construção da sua pesquisa historiográfica com a adoção das fontes e análise documental em diferentes áreas do conhecimento; Lüdkee André (1986), que discutem a relevância de confrontar os dados durante o processo de pesquisa; Sá-Silva et al.(2009), com elementos da pesquisa documental, que aborda sobre pistas teóricas e metodológicas, entre outros.

Compreendemos sobre os processos inerentes à pesquisa documental e histórica, a partir dos estudos sobre a memória individual, pautando em autores como Bosi (1994), Esquinsani (2012), Halbwachs (2006), Gandon (2001), Le Goff (2003) e Ricouer (2007). Com relação à história oral, foram utilizados Alberti (2004) e Ciavatta (2009), que trazem a importância de se trabalhar com relatos e entrevistas na constituição da memória coletiva.

3 A Norma Brasileira de Descrição Arquivística, usada como referência para a classificação e catalogação documental, orienta como proceder para a organização de arquivos em âmbito nacional, foi criada conforme parâmetros internacionais para organização de arquivos de acordo com a General International Standard Archival Description (ISADG). 
A história aqui recontada e registrada a partir das pesquisas é uma tentativa de enfrentamento da condição marginal que a EJA sempre ocupou no processo educacional, especialmente aquela voltada para o meio rural. Pesquisas sobre a EJA foram pouco sistematizadas e divulgadas, o que demanda um compromisso de nossa parte, por considerarmos que a memória é lugar onde cresce a história, que por sua vez a alimenta, fazendo-se necessário sistematizar e refletir sobre o passado para ajudar a compreender o presente e (re)construir, no presente, o futuro. Também consideramos fundamental uma "[...] memória coletiva que sirva para a libertação e não para servidão dos homens" (LE GOFF, 2003, p. 471).

As mencionadas contribuiçóes teórico-metodológicas foram utilizadas no decorrer do processo, associando-as a outras formas de organização documental, pensadas por historiadores, na perspectiva de buscar um tratamento da documentação que respeitasse o movimento educacional, a dinâmica da história produzida pela EJA, tanto pelos movimentos sociais quanto pelos sistemas oficiais de ensino.

Trilhando o caminho dos estudos, bem como da organização do acervo do CMV, foram criadas as fichas catalográficas, que trariam as informaçóes disponíveis no documento para serem lançadas no banco de dados. Inclusive, uma parcela das pesquisas já está disponível no endereço <www.fe.ufg.br/nedesc/ cmv>. Nesse processo de higienização, catalogação, descrição e escaneamento, o subprojeto Movimento de Educação de Base em Goiás (MEB-GO) já tem organizados 509 documentos, dos quais 283 já estáo disponibilizados online. No processo de organização, delimitaram-se as categorias para distribuição do acervo em seçóes, séries e dossiês, de acordo com a Nobrade. Consideramos as orientaçôes dessa norma arquivística por ser de âmbito nacional e adaptar as normas internacionais à realidade brasileira, o que possibilitou que pudéssemos fazer parte de uma rede internacional de informação e documentação relacionada à EJA, a Adult Learnnig Documentation and Information Network (Aladin).

Paralelamente à localização, higienização, organização e postagem dos documentos no banco de dados, houve a sistematizaçáo e registro por escrito, filmagens/vídeos, fotos, bem como foram realizados estudos e análises, o que resultou em publicação de artigos (apresentados em eventos e publicados); produção de relatórios de pesquisa (PIBIC, encaminhados às agências financiadoras); seminários da pesquisa e divulgação no site do Fórum de EJA (<www.forumeja.org.br/cr>).

Nesses escritos procuramos ainda expor as discussóes advindas do Obeduc, que trazem os desafios da Educação de Jovens e Adultos integrada à Educação Profissional. A pesquisa nesse âmbito tem buscado as identidades dos sujeitos, o currículo integrado e o mundo do trabalho. 


\section{Os conceitos de trabalho e educação tecidos na pesquisa}

No âmbito da EJA e educaçáo profissional, com ênfase na concepção de educação emancipatória e na opção pelo currículo integrado, tem-se pautado nos aportes teóricos marxiano, gramsciano, freireano, vygotskyano, entre outros, por compreendermos que tomar a EJA no diálogo com as diferenças culturais, sociais e educacionais dos trabalhadores-estudantes é concebê-la a partir de uma inspiração nos princípios humanistas e da educação popular. Educação popular aqui pensada como manifestação cultural do povo, como uma teoria do conhecimento, por ser legitimada e construída nas práticas sociais, nas experiências e histórias de vida dos e pelos sujeitos, cujas práticas pedagógicas são intencionadas na promoção da transformação social, contando com a participação comprometida de todos os sujeitos envolvidos, educandos e educadores, que almejam construir uma sociedade permeada por valores humanos de justiça, igualdade e ética. Dessa forma, esses escritos pretendem fazer uma leitura do trabalho e da Educação Popular em diálogo com a EJA e a EP, em seus aspectos político-pedagógicos a partir de um recorte histórico dos anos 1960 aos dias atuais.

Iniciaremos abordando sobre o trabalho em uma perspectiva histórico ontológica. Nessa direção, segundo Marx:

O que distingue o pior arquiteto da melhor abelha é que ele figura na mente sua construção antes de transformá-la em realidade. No fim do processo do trabalho aparece um resultado que já existia antes idealmente na imaginação do trabalhador. Ele não transforma apenas o material sobre qual opera; ele imprime ao material o projeto que tinha conscientemente em mira, o qual constitui a lei determinante do seu modo de operar e ao qual tem de subordinar sua vontade. (MARX, 2004, p. 202).

O trabalho como categoria histórico-ontológica pressupõe a relação orgânica dos homens com a natureza, pois o homem vive da natureza e a natureza é o seu corpo, com o qual tem que permanecer em constante processo para garantir sua sobrevivência. A vida física e mental do homem está interligada com a natureza, que não tem outro sentido senão que a natureza está interligada consigo mesma, pois o homem é uma parte da natureza e, com os outros homens, transforma a realidade; portanto, constitui a história, mas também a si mesmo, aos homens, sendo que nesse processo: 
O primeiro pressuposto de toda a existência humana e, portanto, de toda a história, é que os homens devem estar em condiçóes de viver para poder fazer história. Mas, para viver, é preciso antes de tudo, comer, beber, ter habitação, vestir-se e algumas coisas mais. $\mathrm{O}$ primeiro ato histórico é, portanto, a produção dos meios que permitam a satisfação destas necessidades, a produção da própria vida material, e de fato este é um fato histórico, uma condição fundamental de toda a história, que ainda hoje, como há milhóes de anos, deve ser cumprido todos os dias e todas as horas, simplesmente para manter homens vivos. (MARX; ENGELS, 2001, p. 39).

Portanto, o trabalho deveria lhes proporcionar condiçóes para viver - comer, beber, ter habitação, vestir-se -, em uma relação de dignidade, usufruindo da produção dos meios que permitam a satisfação das suas necessidades, a produçáo da própria vida material. Esse é um fato histórico, uma condição fundamental de toda a história.

Contudo, historicamente o homem não tem se visto como parte da natureza. O trabalho se incorpora da categoria sócio-histórica e assume diversas formas sociais, conforme modos de produção historicamente determinados, que se apropriam do produto social do trabalho; assim o homem se aparta da natureza, destruindo-a, explorando-a e vivendo dela apenas. Da mesma forma como explora a natureza, o homem explora os outros homens. Conforme Marx (2004, p. 208):

O processo de trabalho, quando ocorre como processo de consumo da força de trabalho pelo capitalista, apresenta dois fenômenos característicos. O trabalhador trabalha sob o controle do capitalista, a quem pertence seu trabalho. O capitalista cuida em que o trabalho se realize de maneira apropriada e em que se apliquem adequadamente os meios de produção, não se desperdiçando matéria prima e poupando-se o instrumental de trabalho, de modo que só se gaste deles o que for imprescindível à execução do trabalho. Além disso, o produto é propriedade do capitalista, náo do produtor imediato, o trabalhador. O capitalista paga, por exemplo, o valor diário da força de trabalho. Sua utilização, como a de qualquer outra mercadoria [...] Ao penetrar o trabalhador na oficina do capitalista, pertence a este o valor-de-uso de sua força de trabalho, sua utilização, o trabalho. 
Esse é o acontecimento histórico marcante: a transformação social da força de trabalho em mercadoria. $\mathrm{O}$ contexto moderno inaugura sua matriz social com a instituição da força de trabalho como mercadoria, de modo que o trabalho assalariado se tornou uma configuração histórica do trabalho humano que se materializou sob o modo de produção capitalista. Portanto, numa sociedade capitalista:

1) [há] a separação e alienação entre o trabalhador e os meios de produção;

2) a imposição dessas condições objetivadas e alienadas sobre os trabalhadores, como um poder separado que exerce o mando sobre eles;

3) a personificação do capital como um valor egoísta - com sua subjetividade e pseudo personalidade usurpadas - voltada para o atendimento dos imperativos expansionistas do capital;

4) a equivalente personificação do trabalho. (ANTUNES, 2002, p. 21-22).

E nesse processo o/a trabalhador/a, aluno/a da EJA, que depende da venda da sua força de trabalho para (sobre)viver, muitas vezes, entre comer e estudar, opta por comer - alimentar a si e aos seus, o que provoca inúmeras vezes o afastamento escolar temporário e/ou permanente, pois a marca do/a estudante trabalhador/a, em especial o pai ou mãe de família, é a ter de lutar pelas necessidades básicas de vida, pela via do trabalho. Esses estudantes inserem-se no atual contexto marcado pelo formato de relevante exploração do capital, pautado no modelo neoliberal da economia, que a partir da década de 1980 acelerou o processo de globalizaçáo dos mercados e a mundializaçáo do capital. Sobre a concepção de globalização, Frigotto (1998, p. 13) analisa: "No plano socioeconômico o capital, centrado no monopólio crescente das novas tecnologias microeletrônicas associadas à informática, rompe com fronteiras nacionais e globaliza-se de forma violenta e excludente sem procedentes." Para esse autor o referido período histórico, no contexto ético e político, significa a confirmação da visão neoliberal de um novo modelo econômico em que o mercado impera como condição única de sobrevivência da sociedade dos homens. No período neoliberal a:

[...] sociedade contemporânea vem presenciando profundas transformaçôes, tanto nas formas de materialidade quanto na esfera da subjetividade, dadas as complexas relaçôes entre essas formas de ser e existir da 
sociabilidade humana. A crise experimentada pelo capital, bem como suas respostas, das quais o neoliberalismo e a reestruturação produtiva da era da acumulação flexível são expressão, têm acarretado, entre tantas consequências, profundas mutaçóes no interior do mundo do trabalho. Dentre elas podemos inicialmente mencionar o enorme desemprego estrutural, um crescente contingente de trabalhadores em condiçóes precarizadas, além de uma degradação que se amplia, na relação metabólica entre homem e natureza, conduzida pela lógica societal voltada prioritariamente para a produção de mercadorias e para a valorização do capital. (ANTUNES, 2002, p. 15).

Nesse contexto, o sistema capitalista toma a escola como lócus de formação para o mercado de trabalho. Contudo, é essa a função que compreendemos para a formação educacional? De que educação estamos falando? A que possibilita transformar a sua, a minha, a nossa vida? Qual o sentido da escola para jovens e adultos? Freire (2001, p. 35) destaca:

Não devemos chamar o povo à escola para receber instruçóes, postulados, receitas, ameaças, repreensóes e puniçôes, mas para participar coletivamente da construção de um saber, que vai além do saber de pura experiência feito, que leve em conta as suas necessidades e o torne instrumento de luta, possibilitando-lhe ser sujeito de sua própria história.

Como pensar a relação trabalho e educação? Um dos caminhos é aprofundar as formas que vão assumindo as relações de trabalho historicamente e refletir a natureza das contradiçôes que emergem dessas relaçóes. $\mathrm{Na}$ argumentação de Frigotto:

Trata-se de pensar a especificidade da escola não a partir dela, mas das determinaçôes fundamentais: as relaçôes sociais de trabalho, as relaçóes sociais de produção. Tratase, principalmente, de compreender que a produção do conhecimento, a formação da consciência crítica tem sua gênese nessas relaçôes. (2002, p.18).

Consideramos que para trabalhar na educação com o povo, e não só para o povo, a educação popular seja fundamental. Trata-se de uma educação que dialogue com vários conceitos constituídos no contexto histórico. Esse 
ideário de uma educação popular tem sido tratado: como sinônimo de luta pela educaçáo para todos e responsabilidade do Estado por Paiva (1984, 2003) e por Beisiegel (1992); como educação do oprimido por Freire (1984, 1987), no contexto da formação do "[...] homem convertido em classe. É o homem libertado" (BRANDÁO, 1980, p. 129); na defesa dos interesses das classes populares, com vistas à construção da sua própria identidade cultural, por Jiménez (1988); nas práticas voltadas para o exercício da cidadania, em que as maiorias populacionais possam assumir o seu papel sócio-político na conjuntura, como política de resistência dos grupos populares, na busca por mudanças (BEZERRA, 1980); articulado ao conceito de classes populares, que traduz os interesses dessa classe, do povo (WANDERELY, 1980); e articulado aos movimentos sociais populares (PALUDO, 2010, 2011). Trabalharemos aqui com a concepção apontada por Freire: "Aos esfarrapados do mundo, e aos que neles se descobrem e, assim descobrindo-se, com eles sofrem, mas sobretudo, com eles lutam" (FREIRE, 1987, p. 3).

\section{Educação Popular na construção da formação dos jovens e adultos trabalhadores}

Trata-se de uma opção política de atuar com a classe trabalhadora e a serviço dessa classe. E para tal temos pautado nosso fazer-pensar nos referidos princípios da Educação Popular libertadora, crítica, que busca a coerência entre a teoria e o que se vivencia na prática, pois, segundo Paulo Freire, "[...] a coerência é o maior desafio do educador progressista" (2004, p. 120). Princípios que tomam educandas(os) e educadoras(es) como sujeitos históricos do processo educativo.

No que tange à construção, desenvolvimento e avaliação do trabalho educativo da EJA nos pautamos na pesquisa em educaçáo como princípio no processo ensino-aprendizagem; no compromisso ético-político com a classe trabalhadora, explicitado na permanente intencionalidade política do ato educativo, na formação com consciência crítica e na organização/mobilização dos excluídos com vistas à transformação social. Trata-se de uma educação desafiadora/problematizadora, visto que instigará a curiosidade e atenderá os interesses e necessidades dos educandos.

Para tanto, são fundamentais: a análise crítica da realidade, a ação, a consciência crítica, a politização e a conscientização de classe. Para pensar na construção do currículo da EJA é necessário compreendê-lo como um processo 
significativo, que valorize os conhecimentos populares e científicos e estabeleça vínculos com a prática social. Há de se pautar no respeito à linguagem popular dos educandos; na apropriação da linguagem padrão, cuja leitura da palavra deve ampliar a leitura de mundo para dar sentido e significado à leitura da palavra, mediante a leitura crítica da realidade e da palavra; numa prática educativa baseada na totalidade concreta; numa formação humana, integral, interdisciplinar, pautada em princípios ético-morais; no papel do/a educador(a) que toma a educação como ato político, com opçáo e compromisso de classe, no exercício da mediação com vistas à (re)construção dos conhecimentos, saberes e práticas.

Referencia-se em saberes produzidos historicamente por todos, nas relaçóes sociais que se estabelecem entre indivíduos e deles com o meio, embora sejam eles apropriados e organizados pela classe dominante, como se fosse de sua exclusividade, e desvalorizados os saberes produzidos e organizados pela classe trabalhadora como não saberes. E o trabalhador possui saberes, construídos historicamente, ainda que não estejam sistematizados, o que Paulo Freire (1987) denomina saberes de experiência feitos, ao que Vygotsky (1991) chama saberes cotidianos e Gramsci (2004) senso comum e/ou núcleo sadio do senso comum, o bom senso.

Ao afirmar-se que existe um saber intrínseco ao trabalhador e à sua classe, quer-se dizer que, nas relaçóes sociais de produçáo de sua existência, individual e coletivamente, mesmo sob as condiçôes adversas da sociedade capitalista, o operário produz conhecimento, detém um saber, tem uma determinada consciência da realidade. (FRIGOTTO, 2002, p. 20).

Ao enfatizar o mundo do trabalho, na sua historicidade, como relação social fundamental que não se reduz à ocupaçáo, tarefa, emprego, mas que não os exclui, e que abarca o conjunto de relaçóes produtivas, culturais, lúdicas, etc., estou querendo sinalizar que aí se situa o lócus da unidade teórica e prática, técnica e política, ponto de partida e chegada das açóes educativas que, na escola, nos sindicatos, na fábrica, interessam à luta hegemônica das classes populares. (FRIGOTTO, 2002, p. 24).

A EJA deveria pautar-se nos saberes e conhecimentos dos sujeitos, nos interesses e necessidades dos/as educandos/as como ponto de partida para a 
elaboração do currículo, das práticas pedagógicasde ensino-aprendizagem, pois essas práticas e saberes estáo imbricadas com uma ação pedagógicopolítica, o que, na Educação Popular, é determinada a partir das açóes desenvolvidas com grupos sociais menos favorecidos e aqueles que se aproximam das causas de luta social pela emancipação de todos e de cada um, quer seja contribuindo no processo de formaçáo de jovens, adultos e idosos na educação básica numa abordagem da educação popular, quer seja em movimentos sociais e de EP.

Conforme a Educação Popular, prática e teoria são indissociáveis, uma vez que todo saber-fazer de mulheres e homens é um saber impregnado de conhecimento. É na Educação Popular que se insere a possibilidade do exercício pleno do fazer pedagógico como um ato político, posto que temos a consciência que a educação não é uma construção neutra. Conforme Paulo Freire (2004), na Pedagogia da Autonomia, fazer educação não é transmitir saberes e conhecimentos; fazer educação é um ato político que promove a superação da consciência ingênua para a construção da consciência crítica.

[...] a tendência democrática não pode significar apenas que um operário manual se torne qualificado, mas que cada cidadão possa tornar-se governante e que a sociedade o ponha, ainda que abstratamente, nas condiçóes gerais de poder fazê-lo: a democracia política tende a fazer coincidir governantes e governados [...] assegurando a cada governado o aprendizado gratuito das capacidades e da preparação técnica geral a essa finalidade. (GRAMSCI, 1991, p. 137).

Dessa forma, quando partimos dos pressupostos que sustentam a Educação Popular, é possível afirmar que as experiências, saberes e conhecimentos dos educandos são o ponto de partida para a elaboração do currículo, que deve partir da discussão sobre a vida cotidiana e sua inserção como sujeitos históricos e sociais. Assim, os educandos participam da discussão - como o faziam nos Círculos de Cultura -, pois passa a haver diálogo entre os sujeitos que participam do processo, e náo um ensino distanciado da realidade social. A proposta de Freire étomar o diálogo como princípio educativo, com a participação de todos no processo ensino-aprendizagem, indistintamente. $\mathrm{E}$ na EP isso é fundamental, em especial na EJA, com sujeitos envolvidos com o mundo do trabalho.

Nos Círculos de Cultura, criados em 1960 por Paulo Freire como espaços educativos em que transitavam diferentes subjetividades e conviviam 
diferentes saberes, bem como nas escolas de São Paulo na gestão do Partido dos Trabalhadores nos anos 1990, os educadores e educandos assumiam a experiência do diálogo de forma coletiva e solidária em todos os momentos do processo educativo. No processo educativo o educador não se envaidece como se fosse o único detentor do conhecimento, mas aquele educador que reconhece sua competência técnica e seu compromisso político com a classe trabalhadora, compromisso de classe da qual também faz parte, com a qual atua em uma escola pública.

Eram nos Círculos de Cultura (movimentos de educação popular dos anos 1960) e nas escolas públicas (final dos anos 1980/1990) que educandos e educadores discutiam temas e palavras geradoras e, a partir delas, a organização do conteúdo e a construção de um currículo que, verdadeiramente, construía a emancipação. Trata-se da construção de um currículo que parte da realidade dos educandos, da escuta aos seus interesses e necessidades, como coletivo de comunidades, e sobre essa escuta se debruçam os educadores, coordenadores, apoios pedagógicos para construírem os temas a serem trabalhados, as redes de conteúdos a serem desenvolvidos interdisciplinarmente, numa perspectiva de formação integral.

Cabe aqui uma retomada histórica, reafirmando-se que uma das características do modo de produção capitalista recai sobre a divisão social e técnica do trabalho e, dessa forma, as mudanças estabelecidas no mundo do capital exigem uma configuração educacional de classe social. Essa perspectiva impôs e continua impondo a concepção de educação que tem historicamente apartado trabalho intelectual e trabalho manual, trabalho simples e trabalho complexo, cultura geral e cultura técnica.

A dualidade histórica brasileira entre educação propedêutica e profissional, a partir de 2005, é questionada por meio do debate do currículo integrado; nesse sentido, deu-se um passo na compreensão das necessidades da educaçáo de jovens e adultos e de sua importância no que tange ao desenvolvimento social do país, a partir dos trabalhadores. A partir do Decreto no 5.478 (BRASIL, 2005), do Programa Nacional de Integração da Educação Profissional com a Educaçáo Básica na Modalidade de Educação de Jovens e Adultos (Proeja)e do Decreto no 5.840 (BRASIL, 2006), ampliou-se a oportunidade de oferta de cursos nos sistemas estaduais, municipais e entidades nacionais de serviço social, propiciando a integração dos cursos de Formação Inicial também no ensino fundamental na modalidade de EJA, o que resultou então na criação do Proeja-FIC (BRASIL, 2007). Trata-se de uma experiência pedagógica da EJA com educação profissional nos anos finais do ensino fundamental, a qual foi acompanhada, registrada e está sendo sistematizada e organizada pela pesquisa 


\section{Obeduc $^{4}$, coordenada pela UFG e disponibilizada no CMV e no Portal do Fórum Goiano de EJA.}

Integrar trabalho, ciência, técnica, tecnologia, humanismo e cultura geral, esse foi o fundamento, conforme Ramos (2005). Isso é, são dimensões indissociáveis no contexto social e na formação dos trabalhadores. Assim, o currículo integrado apresentou-se como uma possibilidade de inserção social para aqueles que foram obrigados a se afastarem do processo de escolarização pelas próprias condiçóes concretas de existência, mas também representava a perspectiva da formaçáo humana, essencial para a condição emancipatória dos homens e mulheres dessa sociedade.

A partir da incorporação do Proeja ${ }^{5}$ na Rede Municipal de Goiânia, os estudos e os diálogos sobre a educação de jovens e adultos e educaçáo profissional se intensificaram e, dessa forma, tornou-se outro eixo da pesquisa. Nesses escritos, estamos procurando nos ater nos estudos teóricos que se tornaram

4 Além de ter sido registrada, resultou em dissertaçōes de mestrado (ARAÚJO, 2014; ARAÚJO, 2015; FRANCISCO, 2015; LACERDA, 2016), cinco trabalhos do Programa Institucional de Bolsas de Iniciação Científica (PIBIC), sendo três da bolsista Andréia Ferreira dos Santos, relacionados à EJA na SME de Goiânia, conforme: 2013-2014: Construção do Currículo no Proeja-FIC/Pronatec da Secretaria Municipal de Educação de Goiânia; 2014-2015: Continuidade do Acompanhamento e Avaliaçâo da Construção do Currículo Integrado no Proeja-FIC/Pronatec da Secretaria Municipal de Educação de Goiânia; 2015-2016: Análise da Formação continuada do Programa Nacional de Integração da Educação Profissional com a Educação Básica (Proeja-FIC), de 2010 a 2015, na Rede Municipal de Educaçáo de Goiânia, sendo que esse último teve continuidade com a bolsista Patrícia de Moraes Fontenele, a qual deu continuidade à pesquisa com dois outros projetos de pesquisa: o de 2016-2017, Formação continuada de apoios técnico-pedagógicos, coordenadores, diretores e professores da Educação de Jovens e Adultos; e o de 2017-2018, Formação continuada de apoios técnico-pedagógicos, coordenadores e professores da Educação de Jovens e Adultos, da Secretaria Municipal de Educação de Goiânia. E ainda três trabalhos de conclusão de curso e vários projetos de pesquisa, dentre eles os projetos de pesquisa de mestrado aprovados no PPGE/FE/UFG, com o título Trajetórias Formativas dos Educadores Populares do Projeto AJA-Expansão, de Maria Margarida de Santana Ferreira Ferro; e outro em processo de seleção no referido programa, com o título A Prática Pedagógica dos Educadores do Projeto AJA-Extensão/SME-Goiânia e suas Implicações no Processo de Alfabetização, de Jéssica Larrayne da Silva; e dois projetos de doutorado que resultaram em teses de doutorado na UnB, além de vários artigos.

5 A Secretaria Municipal de Educação de Goiânia (SME), no período de 2010 a 2012, realizou, em parceria com o Instituto Federal de Educação, Ciência e Tecnologia de Goiás (IFG), a experiência de Educação de Jovens e Adultos integrada à Educaçáo Profissional, denominada Proeja-FIC, numa escola municipal. A partir de 2012, essa experiência foi acompanhada pela pesquisa do Centro Memória Viva Documentaçáo e Referência em Educaçáo de Jovens e Adultos, Educação Popular e Movimentos Sociais do Centro-Oeste (CMV), da Faculdade de Educaçáo da Universidade Federal de Goiás (FE/UFG). No ano de 2014 foi realizada uma pesquisa, universo de 49 participantes, com os educadores do Proeja-FIC, projeto realizado com dez turmas da Rede Municipal da Educação de Goiânia. Essa pesquisa nos trouxe o conhecimento do perfil desses educadores, bem como sua formação e expectativas com a formaçáo continuada, açáo imprescindível para realizaçâo do projeto. 
imprescindíveis para a compreensão da complexidade do trabalho e educação para os trabalhadores-estudantes da EJA.

Dessa forma, Gramsci (2004b), a partir da dimensão omnilateral, ressalta a pertinência de se buscar o sentido da unidade teoria-prática, enfatiza o trabalho na sua historicidade, como unidade social imprescindível, mas não se limita à ocupação, emprego, tarefa, isso é, assinala o trabalho de forma ampliada nas dimensóes das relaçóes produtivas, culturais, ciências, tecnologias e prática, técnica e política. Isso constitui o fundamento das açóes educativas que as escolas, sindicatos, fábricas, prisóes ou outros espaços precisam constituir para contribuir na formação dos trabalhadores.

Nas implicações do ideário da educação popular, Gramsci (2004a, v. I) argumenta que a educação como prática social pode acontecer em vários espaços, a saber, nas reuniōes dos partidos, nas fábricas, na organização dos sindicatos, no processo das greves e mesmo nas prisóes, entre outros espaços. Os espaços das fábricas tornam-se lugares de aprendizagem, o que devem ser sustentadas nos centros ou círculos de cultura.

Conforme Escritos Políticos (2004a, v. 1, 1910-1920), em 1917, Gramsci propóe a criação, em Turim, de uma associação proletária de cultura, na expectativa de inserir a discussão de cultura na ação política e econômica socialista. Em 1920, participou da escola de cultura, promovida pela Revista L' Ordine Nuovo, ocasião em que trazia discussóes e análise sobre a Revolução Russa. Essa dimensão de educação constitui-se na sua intervenção nas relações sociais.

Da mesma forma, os 'lugares de autonomia' e contestadores da lógica capitalista náo estão isentos dela. Portanto, como produtores de educaçáo e cultura que somos, por profissão, temos que construir estratégias questionadoras e transformadoras do próprio processo de produção no qual estamos inseridos. Em qualquer circunstâncias sabemos que 'a resposta só pode ser global, de modo a unificar o que o capitalismo procurou dividir: os operários entre si, mundo da produção e mundo da cultura, escola e fábrica, estudantes e trabalhadores'. (GORZ, 1980, p. 209, grifos do autor).

Todo esse estudo propiciou reflexões que contribuíram para pensar e defender a formação integrada fundamentada na concepção materialista dialética de conhecimento. Essa concepçáo postula que a realidade pode ser conhecida e compreendida pelos homens. "É pela relaçáo entre homemnatureza e homem-homem (pelo trabalho), que o ser humano produz sua 
existência como espécie e como sujeitos singulares" (RAMOS, 2005, p.108). A concepção- Formação Integrada - concerne o sentido de completude, da coesão das partes no seu todo, de integração no distinto. É pensar o processo educativo concretizado a partir de uma totalidade social, com suas inúmeras intervençóes históricas.

A defesa de que a "[...] educação geral se torne parte inseparável da educação profissional em todos os campos onde se dá a preparação para o trabalho" (CIAVATTA, 2005, p. 84) é o que reafirma o sentido do currículo integrado. Essa superação da dicotomia entre trabalho manual e trabalho intelectual incorpora a dimensão intelectual ao trabalho produtivo, afirma a compreensão do trabalho como princípio educativo. Na argumentação de Ciavatta (2005), é a possibilidade de assegurar aos trabalhadores a formação capaz de propiciar condiçóes para sua atuação como sujeito histórico, como dirigentes e cidadáos.

As reflexóes a partir do referido aporte teórico favoreceram um olhar no fazer pedagógico nas escolas em que se observou a possibilidade da concretização da visão dialógica, no ensejo de compartilhar a experiência dos educadores e da real participaçáo dos educandos como atores sociais socializando reflexôes e opiniōes. A busca de enxergar a formação voltada para jovens e adultos trabalhadores, resguardada da constituição de tornarem-se simplesmente máo de obra de baixo custo para atender ao mercado de trabalho, possibilitava a construção da autonomia dos trabalhadores diante do poder econômico e político.

Esses elementos têm sido objeto de inúmeras discussóes na EJA, bem como de pesquisas desenvolvidas no país afora. $\mathrm{Na}$ história brasileira a EJA, alguns movimentos sociais e a educação popular têm enfrentado o debate em que a educação tem o caráter de unidade entre conhecimento e trabalho, embora a sociedade capitalista insista em tratar como dois mundos apartados. A educaçáo integrada tem vivenciado um campo de disputa política na história desse país. Esse é um debate que tem alimentado educadores e trabalhadores, ainda que o poder hegemônico o considere como ideia superada.

\section{Algumas considerações}

Consideramos que a memória é lugar onde cresce a história, que por sua vez a alimenta, procura sistematizar e refletir sobre o passado para contribuir na construção do presente por meio de atores sociais dispostos a interferir na realidade. As pesquisas realizadas pelo CMV têm contribuído com a visibilidade da história vivida pela EJA, educação popular e movimentos sociais em Goiânia, Goiás e no Centro-Oeste. 
Essa história tem sido recontada por aqueles que a construíram por meio de entrevistas, história oral, fontes documentais, etc., o que vem sendo sistematizado em um banco de dados, além de inúmeros trabalhos (artigos, projetos, monografias, dissertaçóes e teses) que têm sido desenvolvidos pelos integrantes e pesquisadores que acessaram dados do CMV, contribuindo, dessa forma, com a reconstrução/ sistematização e ou ampliação da historiografia da EJA, bem como da trajetória da educação popular e movimentos sociais vinculados à EJA.

A leitura dos Movimentos Sociais e da Educação Popular hoje, no Brasil, não pode prescindir do estabelecimento das relaçóes com o que ocorre no continente latino-americano. Conforme Conceição Paludo, em seus escritos Educação Popular e Movimentos Sociais na atualidade (2010) sobre o mapa da situação da América Latina, provocado pela avalanche neoliberal, surpreende pela diversidade de situaçóes, a saber: resistência na perspectiva de assegurar direitos, historicamente conquistados com muita dificuldade, luta por uma refundação democrática de caráter mais radical e processo de assegurar canais de participação nos modelos institucionais em vigor.

A trajetória do trabalho desenvolvido no CMV tem possibilitado mostrar a relevância de restituir a memória dos processos educativos desenvolvidos por meio de fontes orais e documentais. Ainda são desafiadoras para a equipe as metodologias utilizadas na pesquisa, pois a necessidade de conciliar o olhar do pesquisador com as técnicas arquivísticas é uma realidade.

Por último, as pesquisas e estudos apontaram para o necessário diálogo sobre o trabalho, educação e educação profissional, o que nos trouxe a compreensão de que a disputa entre capital e trabalho também apresenta o embate por outros interesses, que se desenvolvem em todos os âmbitos sociais, entre eles, no campo da educação. A possibilidade de chegar aos conhecimentos elaborados e sistematizados historicamente acontece por via da escola. Mas é necessário que se conceba o currículo integrado como possibilidade da formaçáo dos trabalhadores; assim, compreende-se que trabalho, ciência e cultura precisam estar em diálogo permanente com a formação geral e a profissional.

No entanto, a pesquisa tem mostrado o grande desafio na concretização desse currículo integrado, e o quanto ele se encontra na contramão do ideário neoliberal, defendido pelo poder hegemônico. Ousar nos estudos e pesquisas que tomem o currículo integrado como possibilidade de repensar a educação para jovens e adultos significa buscar outra estrutura política e pedagógica voltada para a formação dos trabalhadores, integrando os saberes específicos deles com os conhecimentos sistematizados historicamente.

O trabalho adquire saberes específicos que os responsáveis pela formação desconhecem. E somente quem vivencia a relação com o trabalho é que pode 
desvelar essa especificidade produzida pelos trabalhadores no processo laboral. Assim, para conhecer o trabalho é preciso ouvir quem o executa e a partir dessa escuta considerar as várias reflexôes possíveis, as quais envolvem saber, produção do saber e a relação do trabalhador com esse saber.

\section{Referências}

ALBERTI, Verena. Ouvir contar: textos em História Oral. Rio de Janeiro: FGV, 2004. ANTUNES, Ricardo. Trabalho e precarização numa ordem neoliberal. In: GENTILI, Pablo; FRIGOTTO Gaudêncio (Org.). A cidadania negada. São Paulo: Cortez, 2002. p. 35-48.

ARAÚJO, Nayara Cristina Carneiro de. O retorno à escola: o significado da escolarização para trabalhadores adultos. Dissertação (Mestrado em Educação)Universidade Federal de Goiás, Faculdade de Educação, Goiânia, 2014.

ARAÚJO, Rafael Vieira de. A corporeidade-subjetividade dos educandos trabalhadores do Proeja FIC. Dissertação (Mestrado em Educação) - Pontifícia Universidade Católica de Goiás, Programa de Pós-Graduação em Educação, Goiânia, 2015.

BEZERRA, Aída. As atividades em educação popular. In: BRANDÃO, Carlos Rodrigues. (Org.). A questáo política da educação popular. 2. ed. São Paulo: Brasiliense, 1980.

BRANDÁO, Carlos Rodrigues (Org.). A questáo política da educação popular. Sáo Paulo: Brasiliense, 1980.

BRASIL. Decreto no 5.478, de 24 de junho de 2005. Institui o Programa Nacional de Integração da Educação Profissional com a Educação Básica na modalidade de Educação de Jovens e Adultos-PROEJA. Disponível em: <http://www.planalto.gov. br/ccivil_03/_ato2004-2006/2005/decreto/d5478.htm>. 15 nov. 2017.

BRASIL. Decreto no 5.840, de 13 de julho de 2006. Institui o Programa Nacional de Integração da Educação Profissional com a Educação Básica na modalidade de Educaçáo de Jovens e Adultos- PROEJA. Disponível em: <http:// www.planalto.gov.br/ccivil_03/_ato2004-2006/2006/decreto/d5840.htm>. Acesso em: 15 nov. 2017.

BRASIL. Ministério da Educação. SETEC. Documento Base do Programa Nacional de Integraçáo da Educaçáo Profissional com a Educaçáo Básica na Modalidade de Educaçáo de Jovens e Adultos. Brasília, DF: MEC, 2007. 
CIAVATTA. A formação integrada: a escola e o trabalho como lugares de memória e de identidade. In: FRIGOTTO, Gaudêncio; CIAVATTA, Maria; RAMOS, Marise (Org.). Ensino médio integrado: concepções e contradições. São Paulo: Cortez, 2005.p. 83-105.

CIAVATTA. A. Mediaçóes históricas de trabalho e educação - Gênese e disputas na formação dos trabalhadores (Rio de Janeiro, 1930-60). Rio de Janeiro: Lamparina, CNPq, Faperj, 2009.

CORSETTI, B. A análise documental no contexto da metodologia qualitativa: uma abordagem a partir da experiência de pesquisa do Programa de PósGraduação em Educação da Unisinos. UNIrevista, Rio Grande do Sul, v. 1, n. 1, p. 32-46, jan. 2006.

ESQUINSANI, Rosimar Serena Siqueira. Entre Percursos, fontes e sujeitos: pesquisa em educação e uso da História Oral. Educaçáo Pesquisa, São Paulo, v. 38, n. 1, jan./mar. 2012.

FÁVERO, Osmar. Uma pedagogia da participaçáo. São Paulo: Autores Associados, 2006.

FRANCISCO, Maria Aldina Gomes da Silva. Formaçáo continuada de professores na educaçáo de adolescentes, jovens e adultos: uma experiência da Secretaria Municipal de Educação de Goiânia 2013-2014. Dissertaçáo (Mestrado em Educaçáo)- Universidade Federal de Goiás, Faculdade de Educação. Goiânia, 2015.

FREIRE, Paulo. Educaçáo como prática da liberdade. Rio de Janeiro: Paz e Terra, 1984.

FREIRE, Paulo. Pedagogia do Oprimido. São Paulo: Paz e Terra, 1987.

FREIRE, Paulo. Política e educação. 5 ed. São Paulo: Cortez, 2001.

FREIRE, Paulo. Pedagogia da autonomia: saberes necessários à prática educativa. 23. ed. Rio de Janeiro: Paz e Terra, 2004.

FRIGOTTO, Gaudêncio. Educaçáo, crise do trabalho assalariado e do desenvolvimento: teorias em conflito. In: FRIGOTTO, Gaudêncio (Org.). Educaçáo e crise do trabalho: perspectivas de final de século. Petrópolis: Vozes, 1998. p. 25-54.

FRIGOTTO, G. Trabalho, conhecimento, consciência e a educação do trabalhador: impasses teóricos e práticos. In: GOMES, C. M. et al. Trabalho e Conhecimento: dilemas na educação do trabalhador. Sáo Paulo: Cortez, 2002. p. 13-26. 
GANDON, Tania Risério d'Almeida. Entre Memória e História: tempos múltiplos de um discurso a muitas vozes. In: Projeto História: História e Oralidade. São Paulo: Educ., 2001.

GORZ, André. Crítica da divisão do trabalho. São Paulo: Martins Fontes, 1980.

GRAMSCI, Antonio. Os intelectuais e a organizaçáo da cultura. Rio de Janeiro: Civilização Brasileira, 1991.

GRAMSCI, Antonio. Cadernos do cárcere. v. 1. Tradução de Carlos Nelson Coutinho; co-ediçẫo, Luiz Sérgio Henriques e Marco Aurélio Nogueira. Rio de Janeiro: Civilização Brasileira, 2004a.

GRAMSCI, Antonio. Cadernos do cárcere. v. 2. Tradução de Carlos Nelson Coutinho; co-edição de Luiz Sérgio Henriques e Marco Aurélio Nogueira. Rio de Janeiro: Civilização Brasileira, 2004b.

GRAMSCI, Antonio. Estudos Políticos. v. 1. Tradução de Carlos Nelson Coutinho. Rio de Janeiro: Civilização Brasileira, 2004.

HALBWACHS, Maurice. A Memória Coletiva. Tradução de Beatriz Sidou. São Paulo: Centauro, 2006.

JIMÉNEZ, Marco Raúl Mejía. Tendencias de la cultura y la cultura popular en la educacion popular. Contexto \&Educaçáo, Ijuí, Universidade de Ijuí, n. 9, jan./ mar. 1988.

LACERDA, Cláudio Virote. A Experiência do Proeja-FIC/Pronatec na Secretaria Municipal de Educaçáo de Goiânia: a construçáo do currículo pelos sujeitos da educação de adolescentes jovens e adultos (Eaja). Dissertaçáo (Mestrado em Educação)- Universidade Federal de Goiás, Faculdade de Educação, Goiânia, 2016.

LE GOFF, Jacques. História e memória. Campinas: Editora UNICAMP, 2003.

LÜDKE, M.; ANDRÉ, M.E.D.A. Pesquisa em educaçáo: abordagens qualitativas. São Paulo: EPU, 1986.

MARX, Karl; ENGELS, Friedrich. A ideologia alemã. Tradução de Luiz Cláudio de Castro e Costa. São Paulo: Martins Fontes, 2001.

MARX, Karl. Manuscritos econômico-filosóficos. São Paulo, Boitempo, 2004.

PAIVA, Vanilda Pereira (Org.). Perspectivas e dilemas da educaçáo popular. Rio de Janeiro: Graal, 1984. 
PAIVA, Vanilda Pereira. História da educação popular no Brasil. 6. ed. São Paulo: Loyola. 2003.

PALUDO, Conceição. Movimentos sociais e educação popular: atualidade do legado de Paulo Freire. In: STRECK, Danilo et al. (Org.). Leituras de Paulo Freire: contribuiçóes para o debate pedagógico (II). Brasília, DF: Liber Livro, 2010. v. 1, p. 39-55. Disponível em: <http://www.ufpel.edu.br/fae/ dialogoscompaulofreire/ConceicaoPaludo.pdf>. Acesso em: 15 nov. 2017.

PALUDO, Conceição. Educação Popular e Movimentos Sociais na atualidade: algumas consideraçóes. In: RIBEIRO, Jorge Alberto Rosa da; ROBEIRO, Marlene. (Org.). I Seminário do TRAMSE: Trabalho, Movimentos Sociais e Educação - Redes de Pesquisa. Porto Alegre: Itapuy, 2011. v. 1, p. 22-35.

PIMENTEL, A. O método da análise documental: seu uso numa pesquisa historiográfica. Cadernos de pesquisa, Londrina, n. 114, p. 179-195, nov. 2001.

RAMOS, M. N. Possibilidades e desafios na organização do currículo integrado. In: FRIGOTTO, G.; CIAVATTA, M.; RAMOS, M. N. (Org.). Ensino médio integrado: concepção e contradiçôes. Sáo Paulo: Cortez, 2005. p. 106-127.

RAMOS, M. N. Concepçáo de ensino médio integrado. (Versão ampliada de outro título "Concepção de Ensino Médio Integrado à Educação Profissional", neste foi incorporado discussóes realizadas no seminário promovido pela Secretaria de Educaçáo do Estado do Pará nos dias 08-09/maio/2008). Disponível em:<http://www.iiep.org.br/curriculo_integrado.pdf>. Acesso em: 3 jul. 2010.

RICOEUR, Paul. A memória, a história, o esquecimento. Tradução de Alain François et al. Campinas: Editora da Unicamp, 2007.

SÁ-SILVA, J. R.; ALMEIDA, C.D; GUINDANI, J. F. Pesquisa documental: pistas teóricas e metodológicas. Revista Brasileira de História \& Ciências Sociais, São Leopoldo, ano 1, n. 1, jul.de 2009. Disponível em: <http://www. rbhcs.com/index_arquivos/Artigo.Pesquisa \%20documental.pdf >. Acesso em: 28 set. 2011.

SCHWARTZ, Yves. Trabalho e saber. Revista Trabalho \& Educaçáo, Belo Horizonte, v. 12, n. 1, jan/jun, 2003.

SCHWARTZ, Yves. Trabalho e Saber. In: ALVES, Wanderson Ferreira; MACHADO Maria Margarida (Org.). Trabalho \& Saber: questóes e proposições na interface entre formação e trabalho. Campinas: Mercado das Letras, 2016. p. 177-196. 
TOSCHI, Mirza Seabra; RODRIGUES, Maria Emilia de Castro. Infovias e Educação. Educaçáo e Pesquisa, São Paulo, v. 29, n. 2, p. 313-326, jul./dez. 2013. WANDERLEY, Luiz Eduardo W. Educação popular e processo de democratização. In: BRANDÁO, Carlos Rodrigues (Org.). A questáo política da educaçáo popular. Sáo Paulo: Brasiliense, 1980.

VYGOTSKY, Lev Seminovich. Pensamento e linguagem. São Paulo: Martins Fontes, 1991. 